\title{
A Framework for Predicting Radiologic Physics Achievement among Radiologic Technology Students
}

\author{
Mark M. Alipio * \\ * Faculty of Radiologic Technology, Davao Doctors College, Philippines \\ (e-mail: markalipiort@gmail.com)
}

\begin{abstract}
:
Background: Radiologic Physics is one of the most challenging professional subjects in the Radiologic Technology (RT) field. It encompasses a wide range of physics concept, calculations, and real-life imaging practices. As observed, most of the students failed in this subject, leading to students dropping out early in the course. To circumvent this daunting issue, a framework for predicting the subject's achievement should be developed using various tenets of learning strategies and management.
\end{abstract}

Objectives: This study aims to explore a framework that can predict Radiologic Physics achievement among RT students.

Methodology: Subjects were 954 Radiologic Physics students (480 males and 474 females) randomly selected from 12 Radiologic Technology schools in the Philippines. Their ages ranged from 18 to 22 years (mean age 19.5, SD 2.4). Seven instruments were used to collect data for the study: Physics Learning Strategies Scale, Inventory of Students Attitude Towards Radiologic Physics; Class Involvement Scale; Teacher-Directed Activities Scale; Parental Influence towards Academic Success Scale, and Radiologic Physics Achievement Test. Path analysis was utilized to identify the best fitting framework.

Results: The best fitting framework explained 92\% of Radiologic Physics achievement variance. Cognitive and metacognitive learning strategies, attitudes towards Radiologic Physics, class involvement, teacher-directed activities, and parental influence exerted a positive effect on Radiologic Physics achievement. Teacher-directed activities, parental influence, and attitudes towards the subject had a positive impact towards cognitive learning strategies. Moreover, teacher-directed activities and parental influence exerted a positive effect on class involvement while parental influence had a positive impact on metacognitive learning strategies. Teacherdirect activities, attitudes towards the subject, and parental influence contributed indirectly to achievement via cognitive learning strategies. Teacher-directed activities contributed indirectly to achievement via class involvement. Finally, parental influence contributed indirectly to achievement via metacognitive learning strategies and class involvement.

Implications: A framework for predicting Radiologic Physics achievement among RT students could be used to understand the performance of students and innovate learning strategies in the RT education.

Keywords: Achievement, Framework, Path Analysis, Physics Education, Physics Achievement, Physics Education, Physics Subject, Radiologic Physics, Radiologic Technology 


\section{INTRODUCTION}

Radiologic Technology (RT) education is gaining popularity as more learners commit to discover various facets of the imaging science. With the increasing number of enrollees in the RT academe, teachers are challenged to provide quality instruction. Students, too, are challenged to study; however, a significant number of dropouts and failing students prompted several RT programs to recalibrate the learning system.

Radiologic Physics is one of the most challenging professional subjects in the RT field. It encompasses a wide range of physics concept, calculations, and real-life imaging practices. As observed, most of the students failed in this subject, leading to students dropping out early in the course. To circumvent this daunting issue, a framework for predicting the subject's achievement should be developed using various tenets of learning strategies and management.

Learning depends so heavily on the direction of the students' effort; and learning results will depend on the management of that effort. In observing actual learning and teaching, the control or management or administration of these activities is itself a crucial issue. If it goes wrong, for example if students do not know where a lecture is to take place, or if they do not take a deadline seriously, and so do not submit work in time to get feedback before an exam, learning outcomes suffer.

Therefore, the new educational imperative is to involve students to manage their own learning in a variety of contexts building their own personal learning environments according to recent goals and interests. In fact, physics learning particularly greatly depends on the time and effort the students put in, and whether they invest that time and effort in more or less productive activities.

In school, teachers manage much of students' learning. However, learning is enhanced if students can manage it themselves; moreover, once they leave school, people have to manage most of their own learning. To do this, they need to be able to establish goals, to persevere, to monitor their learning progress, to adjust their learning strategies as necessary and to overcome difficulties in learning. Students who leave school with the autonomy to set their own learning goals and with a sense that they can reach those goals are better equipped to learn throughout their lives.

For several years of teaching radiologic physics, the researcher observed that many students do not know how to manage their own learning. In particular, his students in class do not spare much time in taking notes and reviewing the lessons. Also, he observed that most of their students did not manage efficiently their time for study. Most students were not prepared in class and that they were too much relying to what the teacher was teaching. Most students find difficulty in their retention and proficiency in the skills taught hence, obtained very low grades.

The researcher believe that in order to help students become good Radiologic Physics learners and be successful in their education, it is pertinent that the teachers, and the students themselves, understand how they learn and assess the strengths and weaknesses in their learning strategies so that the school can provide resources and academic support to help the students to better manage their own learning.

To this end, a number of research studies in other countries have examined some studentrelated factors that influence underachievement in physics (Alipio, Felizarte, \& Revilla, nd; Alipio, 2020; Florentino et al., nd). However, these studies, despite their scope and perhaps depth, only examined the influence of one or a combination of some of the following studentrelated variables: age, gender, interest in physics, study habits, test anxiety, attitude towards physics and mathematical ability. Neither did any of the studies provide empirical evidence of any relationship between learning factors and achievement in Radiologic physics. 


\section{OBJECTIVES OF THE STUDY}

This study aims to explore a framework that can predict Radiologic Physics achievement among RT students. Specifically, it attempted to: (1) determine the causal relationship among cognitive and metacognitive learning strategies, attitudes towards Radiologic Physics, class involvement, teacher-directed activities, parental influence, and student achievement in Radiologic Physics; and (2) determine the best fit framework that can predict Radiologic Physics achievement.

\section{METHODOLOGY}

Sample. Subjects were 954 Radiologic Physics students (480 males and 474 females) randomly selected from 12 Radiologic Technology schools in the Philippines. Their ages ranged from 18 to 22 years (mean age 19.5, SD 2.4).

Instruments. Seven instruments were used to collect data for the study: Physics Learning Strategies Scale, Inventory of Students Attitude Towards Radiologic Physics; Class Involvement Scale; Teacher-Directed Activities Scale; Parental Influence towards Academic Success Scale, and Radiologic Physics Achievement Test. The achievement tests were composed entirely of multiple-choice items. The test was designed by three Physics education experts and contained 25 items assessing student understanding of core concepts in Radiologic Physics. These instruments were pretested using Radiologic Physics students in five schools. The pretest results showed that there were no ambiguities in the instruments. The instruments also produced results that were considered to be highly reliable (reliability values were in the range of 0.87 to 0.92 ).

Data Collection and Analysis. The seven instruments were directly administered to the subjects with help of 12 research assistants. Path analysis was utilized to identify the best fitting framework as examined by the following goodness of fit indices: Chisquare/degrees of Freedom, Root Mean Square of Error Approximation, Tucker-Lewis Index and Comparative Index. In identifying the best fitting framework, all the indices must consistently fall within acceptable ranges. Chi-square/ degrees of freedom value should between $\mathrm{O}$ and 2, with its corresponding p-value greater or equal to 0.05 . Root Mean Square of Error Approximation value must be less than 0.05 and its corresponding pclose value must be greater or equal to 0.05. The other indices such as Normed Fit Index, Tucker-Lewis Index, Comparative Index and Goodness of fit index must be all greater than 0.95 . 


\section{RESULTS AND DISCUSSION}

Test of Hypothesized Framework 1

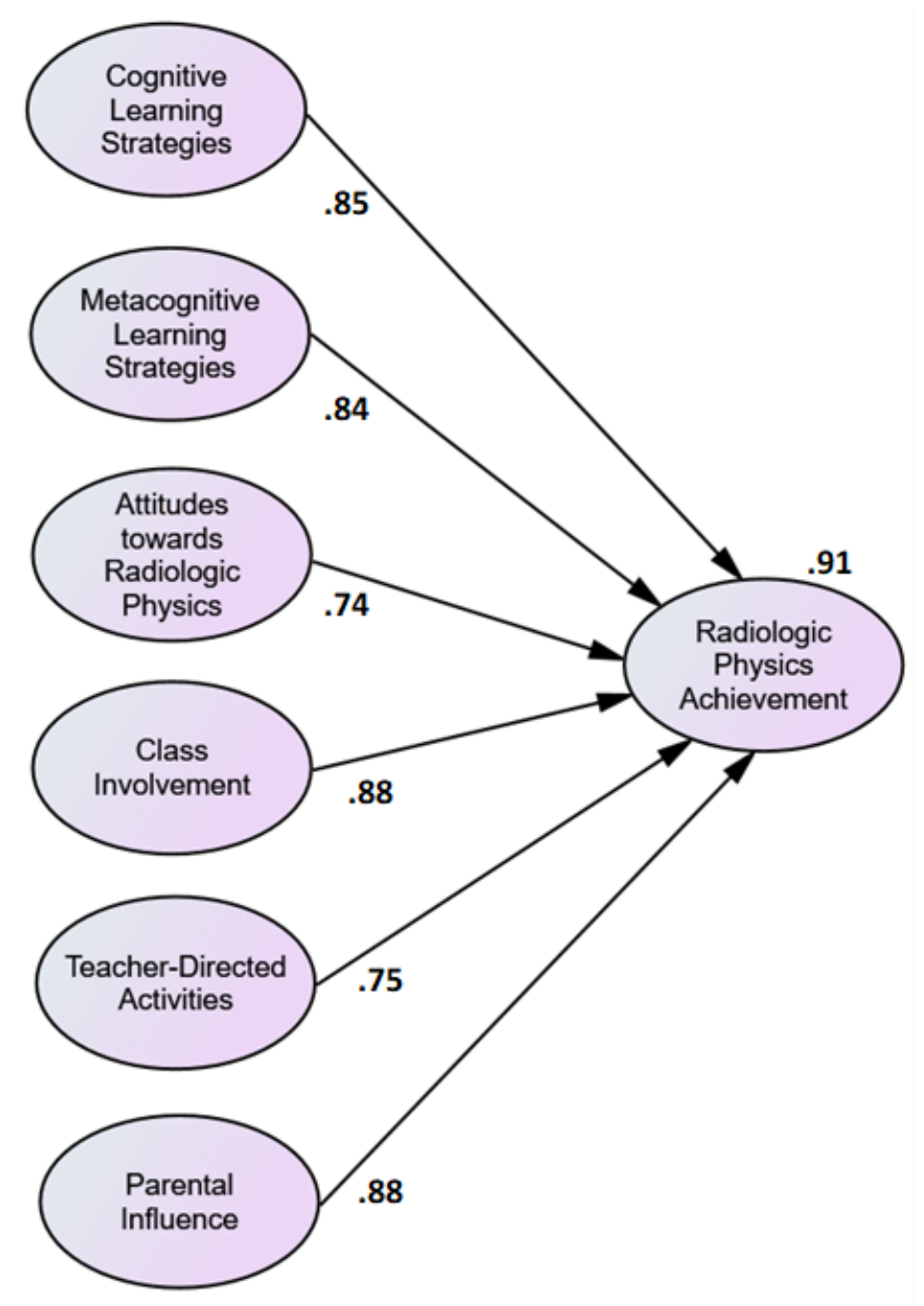

Figure 1. Path Diagram of Framework 1

The first hypothesized framework depicts that cognitive and metacognitive learning strategies, attitudes towards Radiologic Physics, class involvement, teacher-directed activities, and parental influence have a significant direct influence on achievement in Radiologic Physics (Figure 1). Approximately 91\% of Radiologic Physics achievement variance can be explained by the combined effect of cognitive and metacognitive learning strategies, attitudes towards Radiologic Physics, class involvement, teacher-directed activities, and parental influence. The determinants with the greatest causal effect on Radiologic Physics achievement were class involvement and parental influence $(\mathrm{B}=.88)$, followed by cognitive learning strategies $(B=.85)$, metacognitive learning strategies $(B=.84)$, teacher-directed activities $(\mathrm{B}=.75)$, and attitudes towards Radiologic Physics subject $(\mathrm{B}=.74)$. Test for goodness of fit revealed that the hypothesized framework poorly fits the data as manifested by the following indices: $\mathrm{CMIN} / \mathrm{DF}=2.431 ; \mathrm{p}$-value $=.042 ; \mathrm{NFI}=.891 ; \mathrm{TLI}=$ $.884 ; \mathrm{CFI}=.883 ; \mathrm{GFI}=.875 ; \mathrm{RMSEA}=.081 ;$ PCLOSE $=.038$. Chi-square value $(173.014 ; \mathrm{p}$ $=0.000$ ) was evidence of the poor validity of the first hypothesized framework. 
Test of Hypothesized Framework 2

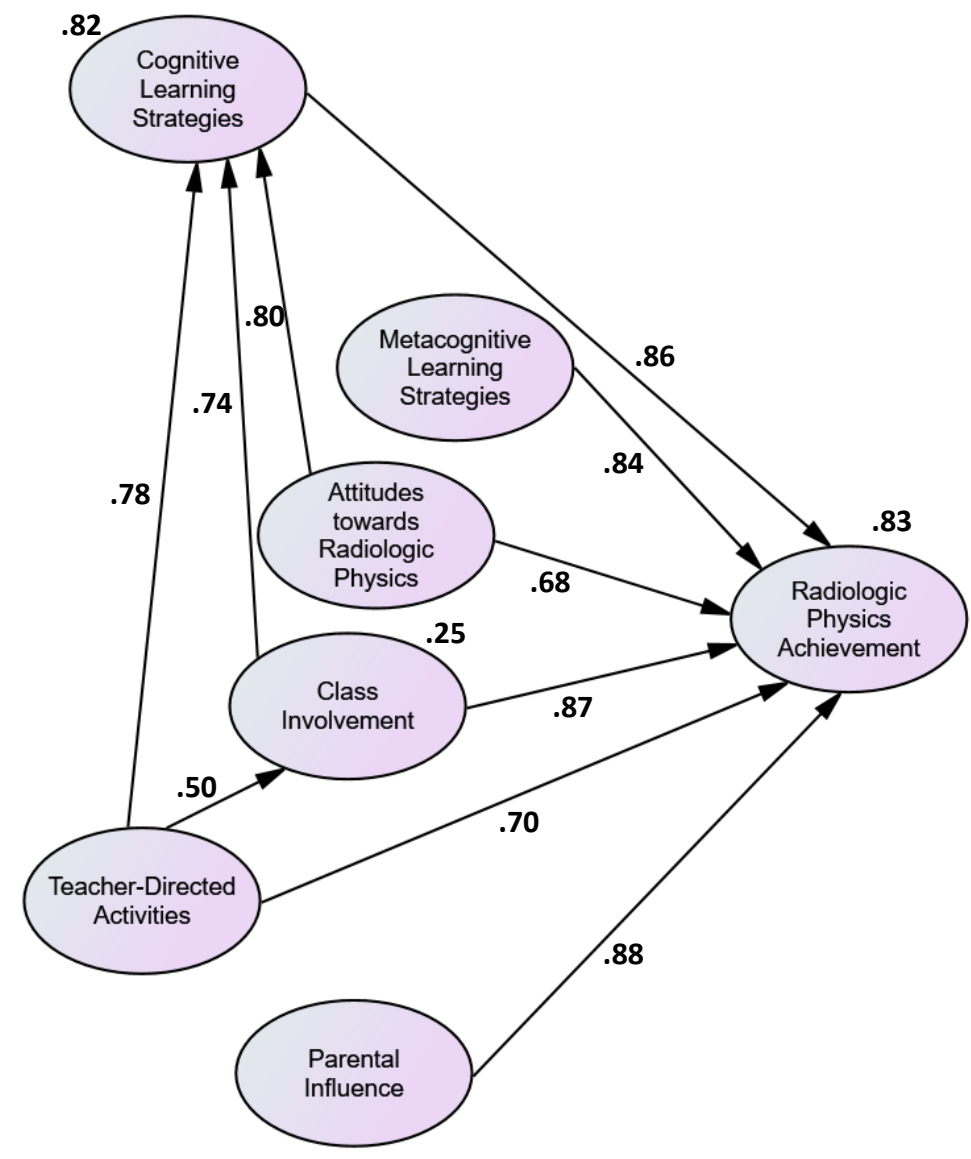

Figure 2. Path Diagram of Framework 2

The second hypothesized framework depicts that cognitive and metacognitive learning strategies, attitudes towards Radiologic Physics, class involvement, teacher-directed activities, and parental influence have a significant direct influence on achievement in Radiologic Physics (Figure 2). Test for goodness of fit revealed that the hypothesized framework fits the data well as manifested by the following indices: $\mathrm{CMIN} / \mathrm{DF}=1.921$; $\mathrm{p}$-value $=.052 ; \mathrm{NFI}=.912 ; \mathrm{TLI}=.931 ; \mathrm{CFI}=.921 ; \mathrm{GFI}=.921 ; \mathrm{RMSEA}=.041 ; \mathrm{PCLOSE}=.068 . \mathrm{Chi}-$ square value $(43.014 ; \mathrm{p}=0.000)$ was evidence of the good validity of the second hypothesized framework. Despite a good framework fit, the total variance in the achievement score decreased when compared to the first framework. Approximately $83 \%$ of Radiologic Physics achievement variance can be explained by the combined effect of cognitive and metacognitive learning strategies, attitudes towards Radiologic Physics, class involvement, teacher-directed activities, and parental influence. The determinant with the greatest causal effect on Radiologic Physics achievement was parental influence $(B=.88)$, followed by class involvement $(B=.87)$, cognitive learning strategies $(B=.86)$, metacognitive learning strategies $(\mathrm{B}=.84)$, teacher-directed activities $(\mathrm{B}=.70)$, and attitudes towards Radiologic Physics subject $(\mathrm{B}=.68)$.

It can be gleaned that teacher-direct activities contributed indirectly to achievement via cognitive learning strategies and class involvement. Class involvement and attitudes towards the subject contributed indirectly to achievement via cognitive learning strategies. Two other outcome variables were presented in the path: cognitive learning strategies and class involvement. Approximately $82 \%$ of cognitive learning strategies variance can be explained by teacher-directed activities, class involvement, and attitudes towards the subject. Of the three determinants of cognitive learning strategies, attitudes towards Radiologic Physics exerted the greatest causal effect $(B=.80)$, followed by teacher-directed activities $(\mathrm{B}=.78)$, and class involvement $(\mathrm{B}=.74)$. Approximately $25 \%$ of the variance in class involvement can be explained by teacher-directed activities $(\mathrm{B}=.50)$. 
Test of Hypothesized Framework 3

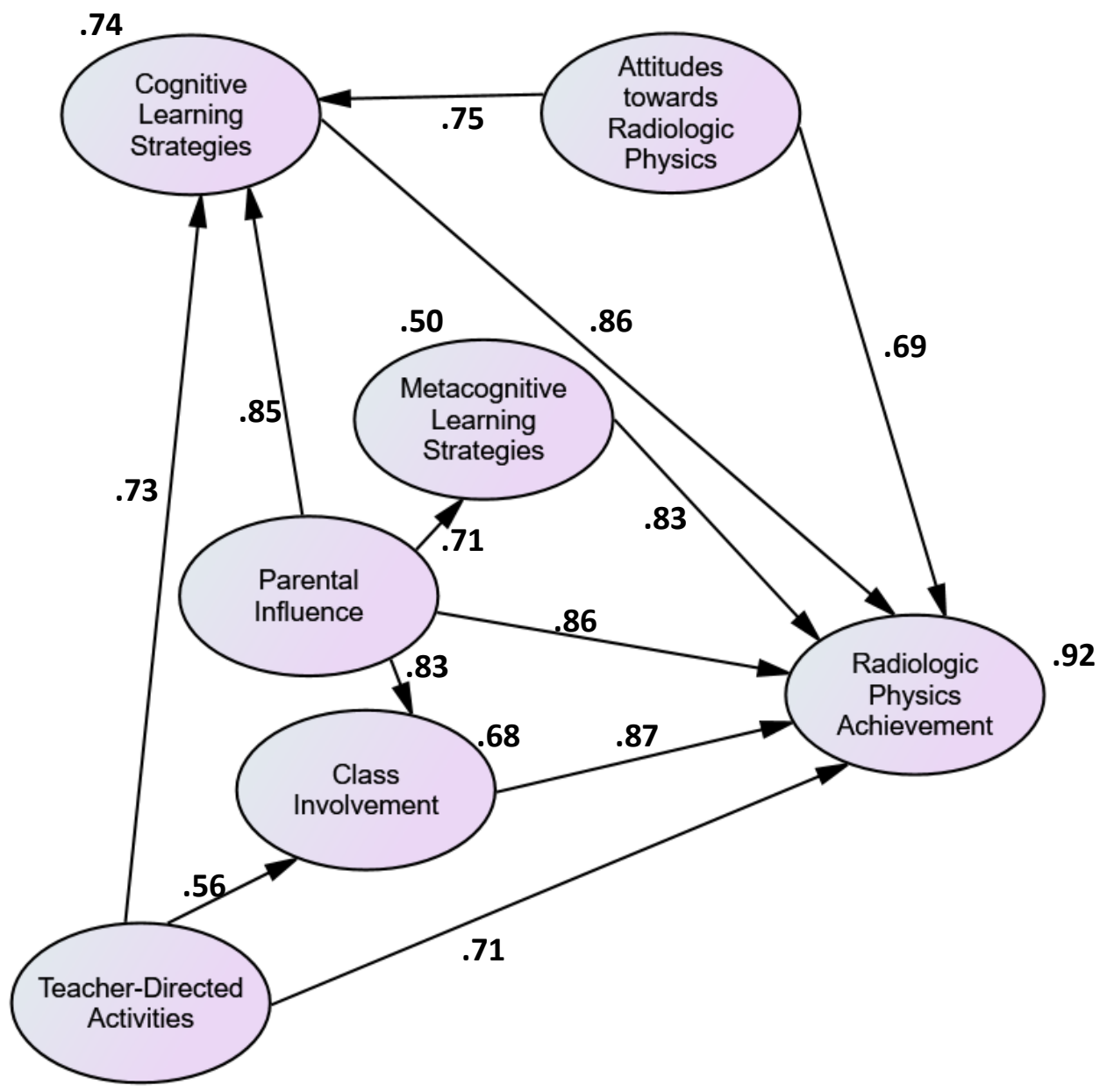

Figure 3. Path Diagram of Framework 3

The third hypothesized framework shows that approximately 92\% of Radiologic Physics achievement variance, higher explained variance compared to the previous hypothesized frameworks, can be explained by the combined direct effect of cognitive and metacognitive learning strategies, attitudes towards Radiologic Physics, class involvement, teacher-directed activities, and parental influence. The determinant with the greatest causal effect on Radiologic Physics achievement was consistent with the previous frameworks and as follows: class involvement $(\mathrm{B}=.87)$, followed by parental influence $(\mathrm{B}=.86)$, cognitive learning strategies $(\mathrm{B}=.86)$, metacognitive learning strategies $(\mathrm{B}=.83)$, teacher-directed activities $(\mathrm{B}=.71)$, and attitudes towards Radiologic Physics subject $(\mathrm{B}=.69)$.

It can be gleaned that teacher-direct activities, attitudes towards the subject, and parental influence contributed indirectly to achievement via cognitive learning strategies. Teacher-directed activities contributed indirectly to achievement via class involvement. Moreover, parental influence contributed indirectly to achievement via metacognitive learning strategies and class involvement.

Three other outcome variables were presented in the path: cognitive learning strategies, class involvement, and metacognitive learning strategies. Approximately $74 \%$ of cognitive learning strategies variance can be explained by teacher-directed activities, parental influence, and attitudes towards the subject. Of the three determinants of cognitive learning strategies, parental influence exerted the greatest causal effect $(\mathrm{B}=.85)$, followed by attitudes towards Radiologic Physics $(\mathrm{B}=.75)$, and teacher-directed activities $(\mathrm{B}=.73)$. Meanwhile, approximately $68 \%$ of class involvement variance can be explained by teacher-directed activities and parental influence. Parental influence 
exerted a higher direct influence on class involvement $(\mathrm{B}=.83)$ compared to teacherdirected activities $(B=.56)$. Finally, approximately $25 \%$ of the variance in metacognitive learning strategies can be explained by parental influence $(B=.71)$.

The model fit statistics reveal the extent to which the third framework improved as compared to the good fit second framework $(\mathrm{CMIN} / \mathrm{DF}=1.762 ; \mathrm{p}$-value $=.072 ; \mathrm{NFI}=.976$; TLI $=.987$; $\mathrm{CFI}=.989 ; \mathrm{GFI}=.991 ; \mathrm{RMSEA}=.032 ;$ PCLOSE $=.231)$. The Chi-square statistic and the likelihood ratio dropped from 43.014 to 21.424 , from 1.921 to 1.762 , respectively. This drop indicates an improvement in the fitting of data. The goodness-of-fit index increased also to a substantial value. The Chi-square difference between the second and third framework was statistically significant at $\mathrm{p}<0.001$ implying that the third framework has a better fit compared to the second framework.

\section{DISCUSSION}

This study explored a framework that can predict Radiologic Physics achievement among RT students. In an attempted to explore a framework, the study aimed to determine the causal relationship among cognitive and metacognitive learning strategies, attitudes towards Radiologic Physics, class involvement, teacher-directed activities, parental influence, and student achievement in Radiologic Physics and to examine the best fit framework that can predict Radiologic Physics achievement.

Several path analyses were conducted to examine the results of causal relationships and the best fit framework. It was very difficult to find a framework that fit the data well, indicating that the variables probably had very complex relationships. The second and third hypothesized frameworks were the best fit; however, because the Chi-square statistic, likelihood ratio, and indices of the third hypothesized framework were significantly improved compared to the second one, the third framework has a better fit compared to the second framework.

In light of the third framework, cognitive and metacognitive learning strategies, attitudes towards Radiologic Physics, class involvement, teacher-directed activities, and parental influence exerted a positive effect on Radiologic Physics achievement suggesting that students who have high awareness of their own knowledge and their ability to understand, control, and manipulate their own cognitive processes could achieve high scores in Radiologic Physics subject. Also, students who are more involved in the class and who have high support from parents could achieve high marks in the subject. Finally, teacher-directed instruction and learning have a positive impact on Radiologic Physics achievement. Hence, Physics classrooms that utilize demonstrations, step-by-step examples of how to solve problems, and different types of assessment could foster excellence in the Radiologic Physics subject.

It is noteworthy to mention the indirect effects of teacher-direct activities, attitudes towards the subject, and parental influence on Radiologic Physics achievement via cognitive learning strategies; teacher-direct activities on Radiologic Physics achievement via class involvement; and parental influence on Radiologic Physics achievement via metacognitive learning strategies and class involvement. Based on the first mediation, it can be argued that the influence of teacher-direct activities, attitudes towards the subject, and parental influence on Radiologic Physics achievement can be interceded by the ability of the students to master cognitive learning strategies such as repetition, organizing new language, summarizing meaning, guessing meaning from context, and using imagery for memorization. The second mediation suggests that the influence of teacher-direct activities on Radiologic Physics achievement can be intervened by involvement of the students in the class. That is, the role of innovative activities given by the teacher to the achievement of the students can be partially or completely enhanced by immersing the students to the activities itself. Future studies may be conducted to determine if the mediation is complete or partial. The third medication suggests that the influence of parental influence on Radiologic Physics achievement can be interceded by metacognitive learning strategies and class involvement. This means that the role of parents' support on the achievement of the students can be improved by the students' mental processes and ability to understand, control, and manipulate their own cognitive functions. Involvement of the students in the class also affect the positive impact of parents' support on Radiologic Physics achievement. 
There were also three outcomes variables in the framework, aside from Radiologic Physics achievement, namely: cognitive learning strategies, class involvement, and metacognitive learning strategies. Teacher-directed activities, parental influence, and attitudes towards the subject had a positive impact towards cognitive learning strategies suggesting that supportive parents and classroom instruction, as well as positive attitude towards the subject, allow students to excellently process learning concepts. Parental influence had the greatest impact on cognitive learning strategies suggesting the importance of parental support on the mental processes of students. On the other hand, teacher-directed activities and parental influence exerted a positive effect on class involvement. Parental influence had a greater impact on class involvement compared to teacher-directed activities implying how significant the role of parents on the involvement of students in the classroom. Finally, parental influence had a positive impact on metacognitive learning strategies implying that if parents are supportive to their children in school, students may have high ability to understand, control, and manipulate their own cognitive processes.

\section{REFERENCES}

Alipio, M. (2020). Predicting Academic Performance of College Freshmen in the Philippines using Psychological Variables and Expectancy-Value Beliefs to OutcomesBased Education: A Path Analysis.

Alipio, M. (2020). Academic Adjustment and Performance among Filipino Freshmen College Students in the Health Sciences: Does Senior High School Strand Matter?

Alipio, M. (2020). Exploring the Clinical Competencies of Radiologic Technologists in Emergency Departments of Selected Hospitals in the Philippines.

Alipio, M. M., Felizarte, L. P., \& Revilla, D. L. PSYCHOSOCIAL FACTORS, EXPECTANCY-VALUE BELIEFS TO OUTCOME-BASED EDUCATION APPROACH AND ACADEMIC PERFORMANCE AMONG FIRST YEAR STUDENTS.

Alipio, M. M., Felizarte, L. P., \& Revilla, D. L. Outcomes-Based Education Approach Correlates and Academic Performance of College Radiologic Technology Freshmen.

Florentino, C. B., Gustilo, R. L., Jailani, H. U., Maceren, M. R., Periabras, N. O., \& Alipio, M. M. The Clinical Competencies of Radiologic Technology Interns of Batch 2018-2019 on Radiological Science Modalities: Basis for Proposed Enhancement Program. 